\title{
Karakteristik Morfologi dan Kelimpahan Populasi Parasitoid (Hymenoptera) pada Hama Invasif Kutu Putih Ubi Kayu, Phenacoccus manihoti Matile-Fererro (Hemiptera: Pseudococcidae) di Bali
}

\author{
I KADEK WISMA YUDHA ${ }^{1}$, I WAYAN SUPARTHA ${ }^{2 *}$, DAN I WAYAN SUSILA ${ }^{2}$ \\ ${ }^{1}$ Program Magister Program Studi Pertanian Lahan Kering, Fakultas Pertanian, Universitas \\ Udayana \\ ${ }^{2}$ Laboratorium Pengelolaan Hama dan Penyakit Terpadu (IPMLaB) Fakultas Pertanian, \\ Universitas Udayana \\ ${ }^{*}$ E-mail: yansupartha@yahoo.com
}

\begin{abstract}
Morphological Characteristics and Populations Abundance of Parasitoid (Hymenoptera) on Invasive Pests Cassava Mealybug, Phenacoccus manihoti Matile-Fererro (Hemiptera: Pseudococcidae) in Bali. This study aims to know the morphological characteristics of parasitoid, population abundance and distribution patterns of parasitoid associated with $P$. manihoti on cassava crop in Bali. The study was conducted on all cassava crop in Bali with a field observation method that was determined by taking shoots of cassava plants attacked by cassava mealybug $P$. manihoti, then cassava mealybug $P$. manihoti were nurtured, then observation was carried out every day until parasitoid appeared and being identified. The results of the study showed that there were three dominant types of parsitoid that were found to be associated with invasive pest $P$. manihoti, namely Anagyrus lopezi, Acerophagus papayae and Blepyrus insularis. The abundance of parasitoid populations was dominated by parasitoid A. lopezi with a range of values $48.6-81.8 \%$. Then followed by parasitoid A. papayae $7.7-37.1 \%$, and B. insularis $3.4-14.3 \%$. The distribution pattern of parasitoid varies in each species, parasitoid A. lopezi spreads in groups categories, Parasitoid A. papayae and B. insularis spread random-regulary on cassava crop throughout on each of the Regencies in Bali.
\end{abstract}

Keywords: Biological Control, Invasive Pest, Parasitoid and Characteristics Morphologica

PENDAHULUAN

Kutu putih Phenacoccus manihoti mulai menjadi perhatian dunia pada saat hama ini secara tidak sengaja terbawa masuk ke Afrika pada tahun 1970 (Nwanze et al., 1979) menyebabkan kegagalan panen 


\section{KADEK WISMA YUDHA. et al. Karakteristik Morfologi dan Kelimpahan Populasi...}

dan kelaparan. Hama ini masuk ke Asia pada tahun 2009, Thailand yang pertama kali melaporkan penemuan hama ini yang kemudian segera menyebar ke Kamboja dan Laos (Winotai et al., 2010; Parsa et al., 2012).

Kutu putih ubi kayu di Indonesia pertama kali dilaporkan di Bogor pada tahun 2010 (Muniappan et al., 2011). Serangan hama ini menyebabkan kehilangan hasil sekitar $82 \%$ di Afrika (Nwanze, 1982) dan 40-50\% di Asia (Wyckhuys et al., 2014; Wardani, 2015). Amarasekare et al. (2008) menjelaskan bahwa di daerah asalnya, serangan hama ini dapat dikendalikan dengan adanya musuh alami seperti parasitoid dan predator.

Afrika, Thailand dan 25 negara lainnya sudah menemukan dan menggunakan agens pengendali hayati seperti Plesiochrysa ramburi dan kumbang Coccinelidae sebagai predator serta Anagyrus lopezi De Santis (Hymenoptera: Encyrtidae) sebagai parasitoid kutu putih ubi kayu (James et al., 2000).

Penelitian yang dilakukan oleh Lohr dan Varela (1990) ditemukan adanya 18 spesies musuh alami menyerang $P$. manihoti pada tanaman ubi kayu di Afrika, yang didominasi oleh parasitoid soliter sepert Epidinocarsisn lopezi (DeSantis) (Hymenoptera: Encyrtidae), Hyperaspis notata Mulsant dan Diomus spp. (Coleoptera: Coccinellidae), dan Ocyptamus spp. (Diptera: Syrphidae). Penelitian ini bertujuan untuk mengetahui karakteristik morfologi parasitoid, kelimpahan relative dan pola sebaran parasitoid yang berasosiasi dengan hama invasif $P$. manihoti pada tanaman ubi kayu di Bali.

\section{BAHAN DAN METODE}

\section{Tempat dan Waktu Penelitian}

Penelitian dilakukan di Lapangan dan di Laboratorium. Lokasi Penelitian lapang dilakukan di seluruh pertanaman ubi kayu di Provinsi Bali yang disajikan pada Tabel 1. Penelitian Laboratorium dilaksanakan di Laboratorium Pengendalian Hama dan Penyakit Terpadu Fakultas Pertanian Universitas Udayana. Penelitian berlangsung dari Bulan Januari sampai Mei 2019. 
AGROTROP, 10 (2): 178 - 189 (2020)

Tabel 1. Lokasi Pengambilan Sampel

\begin{tabular}{|c|c|c|c|}
\hline Kabupaten & Koordinat & $\begin{array}{l}\text { Ketinggian } \\
\text { (Mdpl) }\end{array}$ & Tempat \\
\hline \multirow[t]{5}{*}{ Bangli } & $8^{\prime} 26^{\prime} 18^{\prime \prime S} 115^{\prime} 19^{\prime} 468^{\prime \prime} \mathrm{E}$ & 445 & \\
\hline & 8`26 51"S 115`22`591" E & 449 & \\
\hline & 8`30`49"S 115`20`144" E & 237 & \\
\hline & 8`11`52"S 115`25`51" E & 532 & \\
\hline & $8^{\prime} 13^{\prime} 26 " \mathrm{~S} 115^{\prime} 15^{\prime} 12^{\prime \prime} \mathrm{E}$ & 927 & \\
\hline \multirow{5}{*}{ Gianyar } & $8^{\prime} 28^{`} 52^{\prime \prime}$ S $115^{\prime} 18^{`} 695^{\prime \prime} \mathrm{E}$ & 450 & \\
\hline & $8^{\prime} 28^{`} 36^{\prime \prime} \mathrm{S} 115^{\prime} 12 ` 531 " \mathrm{~S}$ & 146 & \\
\hline & $8^{\prime} 28^{\prime} 72^{\prime \prime} \mathrm{S} 115^{\prime} 35^{\prime} 825^{\prime \prime} \mathrm{E}$ & 503 & \\
\hline & $8^{\prime} 28^{`} 26^{\prime \prime}$ S $115^{\prime} 11^{\prime} 225^{\prime \prime}$ S & 52 & \\
\hline & $8^{`} 28^{`} 56^{\prime \prime} \mathrm{S} 115^{\prime} 18^{`} 725^{\prime \prime} \mathrm{E}$ & 466 & \\
\hline \multirow[t]{5}{*}{ Klungkung } & $89^{\prime} 29^{\prime} \mathrm{S} 115227^{\prime} \mathrm{E}$ & 323 & \\
\hline & $8 ` 30 ` 21 " \mathrm{~S} 11522{ }^{\prime} 46^{\prime \prime} \mathrm{E}$ & 241 & \\
\hline & $8^{`} 30^{`} 11^{\prime \prime} \mathrm{S} 115^{\prime} 24^{\prime} 22^{\prime \prime} \mathrm{E}$ & 207 & \\
\hline & $8^{\prime} 17^{\prime} 32^{\prime} \mathrm{S} 114^{\prime} 31^{\prime} 5^{\prime \prime} \mathrm{E}$ & 20 & \\
\hline & $8^{\prime} 18^{\prime} 22^{\prime \prime S} 114 ` 314^{\prime}{ }^{\prime} \mathrm{E}$ & 15 & \\
\hline \multirow{5}{*}{ Denpasar } & $8^{\prime} 42^{`} 22^{\prime \prime}$ S $115^{\circ} 13^{`} 0^{\prime \prime} \mathrm{E}$ & 17 & \\
\hline & 8`36`11" S 115`13`23" E & 84 & \\
\hline & $8^{\prime} 39^{\prime} 24^{\prime \prime}$ S $115^{\prime} 14^{\prime} 59^{\prime \prime}$ E & 10 & \\
\hline & $8 ` 32 ` 12^{\prime \prime}$ S $115 ` 14 ` 10^{\prime \prime} \mathrm{E}$ & 14 & \\
\hline & $8 ` 365^{\prime}$ S $115 ` 12 ` 56 " \mathrm{E}$ & 77 & \\
\hline \multirow[t]{5}{*}{ Badung } & $8^{\prime} 38^{`} 52^{\prime \prime} \mathrm{S} 115^{\prime} 8^{\prime} 28^{\prime \prime}$ & 29 & \\
\hline & $8^{\prime} 36^{\prime} 20^{\prime \prime} \mathrm{S} 115^{\prime} 9^{\prime} 14^{\prime \prime} \mathrm{E}$ & 76 & \\
\hline & $8^{\prime} 28^{\prime} 27^{\prime} \mathrm{S} 115 ` 127^{\prime} \mathrm{E}$ & 283 & \\
\hline & $8^{\prime} 16^{\prime} 40^{\prime} \mathrm{S} 115^{\prime} 146^{\prime \prime} \mathrm{E}$ & 973 & \\
\hline & 8`21`46“'S 115`13`33“E & 622 & \\
\hline \multirow[t]{5}{*}{ Tabanan } & $8^{`} 34^{\prime} 34^{\prime} \mathrm{S} 1157^{\prime} 56^{\prime} \mathrm{E}$ & 95 & \\
\hline & 8`28`59“'S 115`5 52“Е & 184 & \\
\hline & $8^{\prime} 28^{\prime} 59^{\prime \prime} \mathrm{S} 1155^{\prime} 52^{\prime \prime} \mathrm{E}$ & 622 & \\
\hline & $8311^{\prime} 32^{\prime \prime} \mathrm{S} 115025^{\prime \prime} \mathrm{E}$ & 51 & \\
\hline & $8^{\prime} 19^{\prime} 59^{\prime \prime} \mathrm{S} 115 ` 1 ` 52^{\prime \prime} \mathrm{E}$ & 732 & \\
\hline \multirow[t]{5}{*}{ Negara } & $8.259^{\prime \prime S} 114488^{\prime} 28^{\prime \prime} \mathrm{E}$ & 9 & \\
\hline & $8^{\prime} 23^{\prime} 20^{\prime} \mathrm{S}$ 114 $44322^{\prime} \mathrm{E}$ & 15 & \\
\hline & 8`21`15`S 114`37 55`E & 26 & \\
\hline & 8`15 46“`S 11429`19`E & 28 & \\
\hline & 8`17‘32“S 114331`5“E & 38 & \\
\hline \multirow{5}{*}{ Buleleng } & $8^{\prime} 8^{\prime} 7^{\prime \prime} \mathrm{S} 115 ` 1922{ }^{\prime} \mathrm{E}$ & 375 & \\
\hline & 8`531“S 115950“Е & 69 & \\
\hline & $8942 “ \mathrm{~S} 1152245^{\prime \prime} \mathrm{E}$ & 37 & \\
\hline & 8`11 57``S 115 49`21`E & 17 & \\
\hline & 8`14`18“'S 114 56 53“Е & 281 & \\
\hline \multirow[t]{5}{*}{ Karangasem } & $8^{`} 30^{\prime} 46^{\prime} \mathrm{S} 115^{\prime} 30^{\prime} 0^{\prime} \mathrm{E}$ & 19 & \\
\hline & $8^{\prime} 288^{\prime} 0 ` \mathrm{~S} 1153712 ` \mathrm{E}$ & 43 & \\
\hline & $8^{\prime} 26^{\prime} 18^{\prime} \mathrm{S} 115^{\prime} 33^{\prime} 15^{\prime} \mathrm{E}$ & 343 & \\
\hline & 8`19`11“S 115`373“Е & 41 & \\
\hline & $8 ` 12 ` 21 “ \mathrm{~S} 115300^{\prime} 25^{\prime \prime} \mathrm{E}$ & 11 & \\
\hline
\end{tabular}


I KADEK WISMA YUDHA. et al. Karakteristik Morfologi dan Kelimpahan Populasi...

\section{Pelaksanaan Penelitian}

Bahan yang digunakan dalam penelitian ini adalah: tanaman ubi kayu varietas UJ5, Adira 1 dan Malang 6 yang dijumpai di lapang rata-rata umur 1 hingga 6 bulan, kutu putih $P$. manihoti, parasitoid, gelas plastik, air, alkohol 70\%. Alat-alat yang digunakan dalam penelitian ini adalah: alat tulis, handcounter, botol koleksi, mikroskop, opti Lab, GPS, kuas, kamera, dan kurungan pembiakan.

Penentuan lokasi pengambilan sampel (unit sampel) pada tanaman ubi kayu disetiap kabupaten dilakukan secara diagonal, sehingga didapatkan lima unit sampel. Luas masing-masing unit sampel adalah $\pm 500 \mathrm{~m} 2$. Pengambilan sampel daun (pucuk) ubi kayu terserang kutu putih pada unit sampel dilakukan secara porposif dengan mengambil sejumlah 5 pucuk tanaman ubi kayu pada setiap unit sampel. Sampel daun atau pucuk yang terserang kutu putih kemudian disimpan dalam kantong plastik di isi label dan tempat pengambilan sampel, selanjutnya dibawa kelaboratorium. Pengamatan terhadap kemunculan parasitoid dilakukan setiap hr. Parasitoid yang muncul selanjutnya dilakukan identifikasi menggunakan acuan dari Noyes \& Hayat 1994; Noyes, 2000.

\section{Penyajian Data}

Data karakteristik morfologi parasitoid disajikan dalam tabel, hasil formulasi kelimpahan parasitoid ditampilkan dalam bentuk gambar dan hasil formulasi pola persebaran parasitoid ditampilkan dalam bentuk tabel.

Pola sebaran populasi parasitoid mengacu pada formula dari: Fowler \& Cohen 1990

$$
\mathrm{S}^{2}=\frac{\mathrm{z}[\mathrm{Xi}-\mathrm{X}]}{\mathrm{n}-1}
$$

Keterangan:

$S^{2}$ : Pola Sebaran

$\mathrm{Xi}$ : Jumlah individu spesies ke-i

$\mathrm{X}$ : Total rata-rata individu

$\mathrm{n}$ : Total sampling.

Kriteria : $S^{2}<1$ : Pola sebaran teratur, $S^{2}=1$ : Pola sebaran acak

$S^{2}>1$ : Pola sebaran mengelompok

Kelimpahan relatif (Krebs, 1989)

$$
\mathrm{Kr}=\frac{K i}{\mathbb{E} K} \times 100 \%
$$

Keterangan:

$\mathrm{Kr}$ : Kelimpahan relative spesies

$\mathrm{Ki} \quad$ : Kelimpahan spesies ke-i : Jumlah kelimpahan semua spesies 


\section{HASIL DAN PEMBAHASAN}

1. Karakteristik Morfologi Parasitoid

Hama $P$. manihoti pada Pertanaman

\section{Ubi Kayu di Bali}

Hasil penelitian menunjukkan ditemukan tiga jenis parasitoid kutu putih Phenacoccus manihoti. Ketiga parasitoid tersebut yaitu
Anagyrus lopezi (De Santis), Acerophagus papayae (Noyes \& Schauff), Blepyrus insularis (Cameron) (Hymenoptera: Encyrtidae). Adapaun karakteristik morfologi ketiga parasitoid tersebut disajikan dalam Tabel 2, Tabel 3 dan Tabel 4 berikut:

Tabel 2. Karakteristik Morfologi Anagyrus lopezi
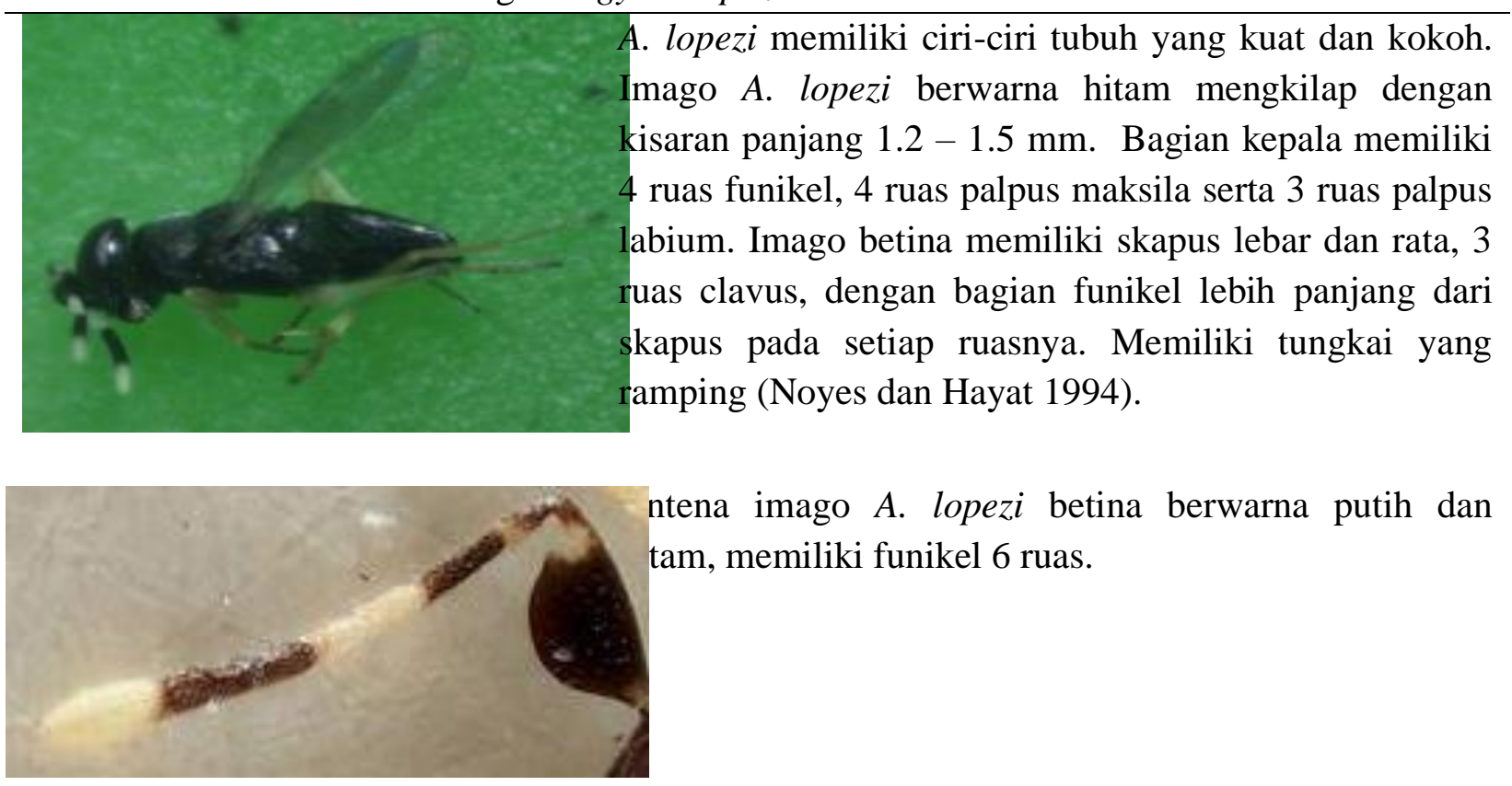

Pada bagian sayapnya terdapat vena submarginal yang tidak lebih besar dari stigma, gaster lebih pendek dari toraks. 
I KADEK WISMA YUDHA. et al. Karakteristik Morfologi dan Kelimpahan Populasi...

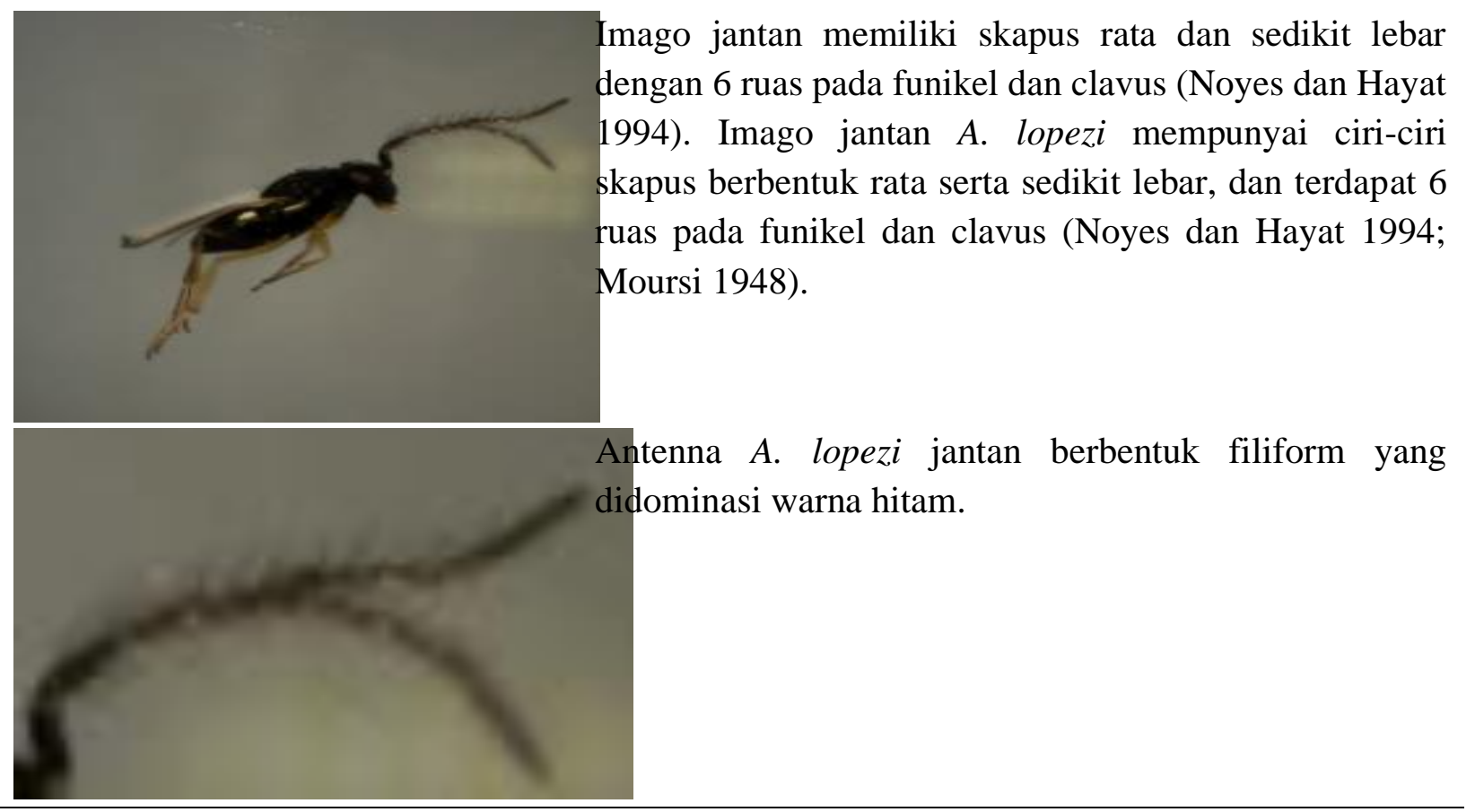

Tabel 3. Karakteristik Morfologi Acerophagus papayae

Panjang tubuhnya $0,85 \mathrm{~mm}$. Kepala berwarna oranye
pucat, memiliki mata majemuk kehijauan, dan mata
ocelli berwarna merah. Bagian torak berwarna oranye
pucat, bagian scutellum. Sisi torak lateral dan tungkai
sedikit lebih pucat daripada sisi torak dorsal. (Noyes \&
Schauff, 2003).

Bagian antenna berwarna kuning pucat dengan dasar club sedikit kehitaman. 


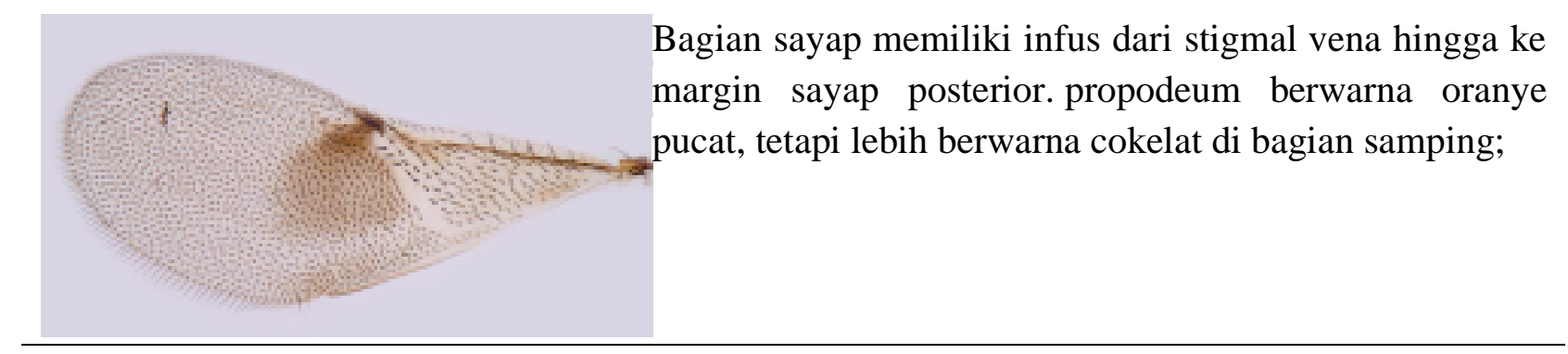

Tabel 4. Karakteristik Morfologi Blepyrus insularis
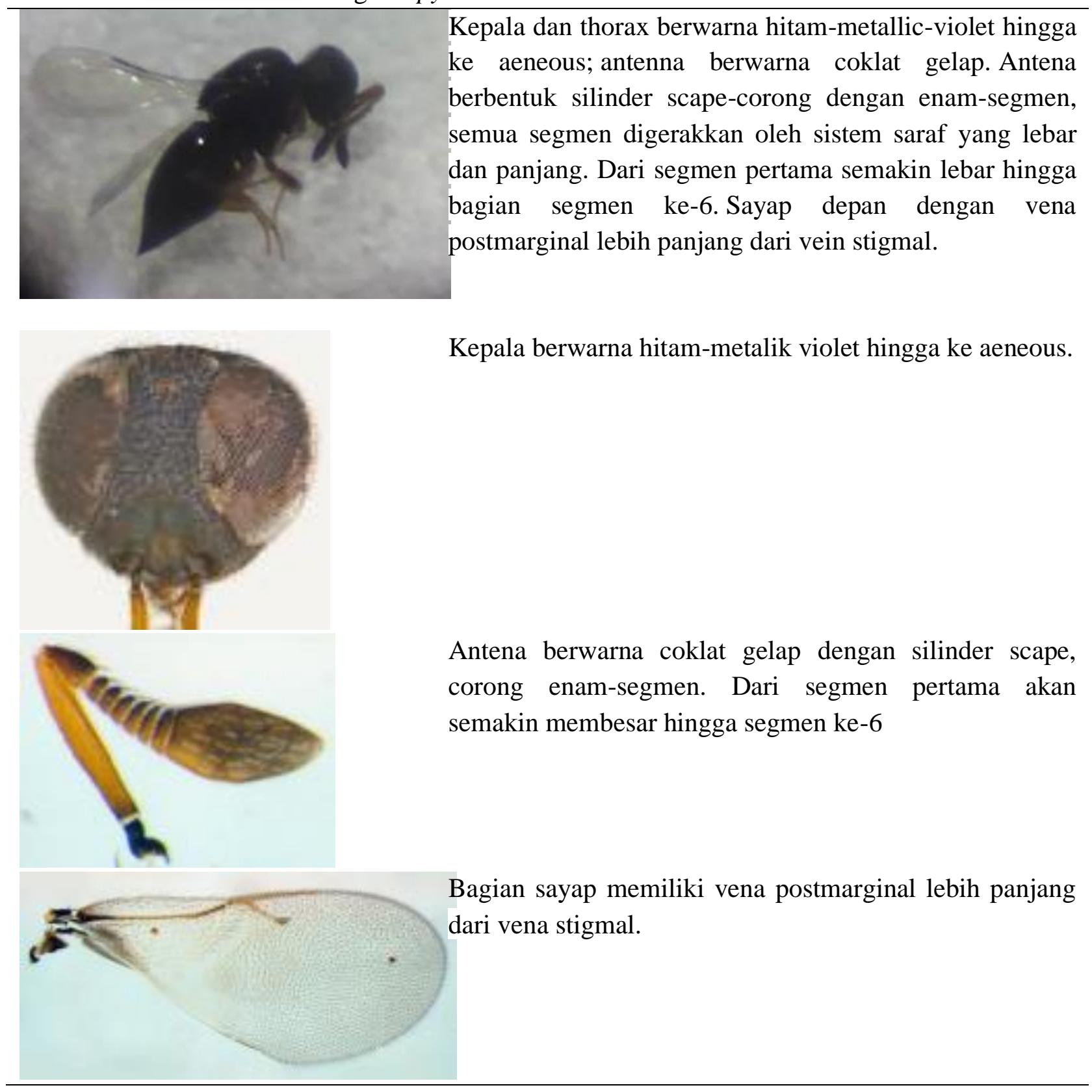


\section{KADEK WISMA YUDHA. et al. Karakteristik Morfologi dan Kelimpahan Populasi...}

2. Kelimpahan Relatif Parasitoid Hama P. manihoti pada Pertanaman Ubi

\section{Kayu di Bali}

Ditemukan tiga jenis parasitoid hama P. manihoti yaitu Anagyrus lopezi, Acerophagus papayae dan Blepyrus insularis. Kelimpahan parasitoid A. lopezi bekisar antara 48,6 - 81,8\%. Kelimpahan parasitoid A. papayae sebesar $7,7-37,1 \%$, sedangkan parasitoid B. insularis sebesar 3,4 - 14,3\% (Gambar 3.1). Supartha (2003) mengungkapkan kelimpahan di lapang dipengaruh oleh faktor intrinsik dan faktor ekstrinsik. Faktor ektrinsik seperti ketahanan inang kutu putih $P$. manihoti yang mampu men-enkapsulasi telur dari parasitoid sehingga menyebabkan perkembangan parasitoid tidak menjadi optimal pada instar awal (Giordanengo dan Nenon, 1990). Sedangkan faktor ekstrinsik seperti faktor lingkungan meliputi kecukupan makanan, iklim, ruang dan kompetisi (Supartha et al., 2005). Kestabilan dari lingkungan pada masing-masing daerah pertanaman ubi kayu juga mempengaruhi kelimpahan dari musuh alami (Aquilino et al., 2005). Pola tanam tumpang sari yang dilakukan pada tanaman budidaya juga mempengaruhi meningkatannya peran parasitoid dalam menangani iangnya (Wahyuni, 2017). Sistem pertanaman campuran juga meningkatkan stabilitas dari parasitoid, melalui peningkatan peran musuh alami yang disebabkan oleh ketersediaannya sumber nutrisi seperti nektar bagi parasitoid (Paulsen et al., 2006; Adow, 1991; Altieri, 1999).

Kemampuan parasitoid akan semakin tinggi bila adanya ketersediaan pakan, inang dan tanaman yang menghasilkan nutrisi seperti madu di sekitar pertanaman ubi kayu (Baggen dan Gurr, 1998). Adanya sumber daya pendukung (inang alternatif, shelter, refugia area, lingkungan mikro) berpengaruh positif terhadap lama hidup parasitoid (Nicholls dan Alfieri, 2003). 


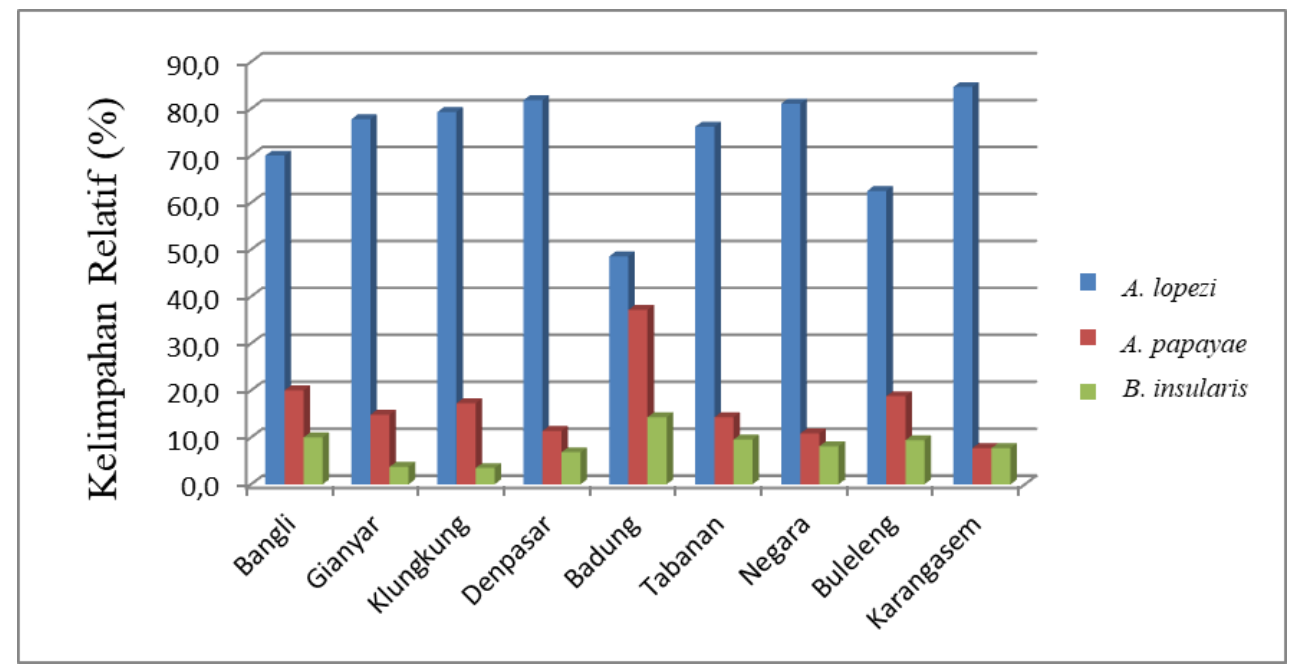

Gambar 1. Kelimpahan relatif parasitoid hama $P$. manihoti pada petanaman ubi kayu di Bali

3. Pola Sebaran Parasitoid Hama $\boldsymbol{P}$. Kabupaten Tabanan, Jembrana dan manihoti pada Pertanaman Ubi Karangasem. Pola sebaran acak dari Kayu di Bali

parasitoid A. papayae berada di Kabupaten

Hasil penelitian menunjukkan pola Klungkung dan Denpasar dan pola sebaran sebaran dari ketiga parasitoid Anagyrus mengelompok yang berada di Kabupaten lopezi, Acerophagus papayae dan Blepyrus Bangli, Gianyar, Badung dan Buleleng. insularis memiliki kategori yang berbedabeda. Tabel 5. menunjukkan pola sebaran parasitoid A. lopezi tergolong dalam kategori menyebar secara mengelompok $(>1)$ diseluruh kabupaten di Bali. Parasitoid A. papayae memiliki kategori yang beragama dalam pola sebarannya di lapang. Parasitoid Parasitoid B. insularis memiliki pola sebaran yang beragam dari sebaran teratur yang berada pada Kabupaten Bangli, Gianyar, Klungkung, Denpasar, Tabanan, Jembrana, Buleleng dan Karangasem. dan di Kabupaten Badung parasitoid B. insurasi menyebar secara acak.

A. papayae menyebar secara teratur di 


\section{KADEK WISMA YUDHA. et al. Karakteristik Morfologi dan Kelimpahan Populasi...}

Tabel 5. Pola sebaran parasitoid hama P. manihoti pada pertanaman ubi kayu disluruh kabupaten di provinsi Bali

\begin{tabular}{llllllllll}
\hline $\begin{array}{l}\text { Spesies } \\
\text { Parasitoid }\end{array}$ & Bangli & Gianyar & Klungkung & Denpasar & Badung & Tabanan & Jembrana & Buleleng & Karangasem \\
\cline { 2 - 9 } & Pola Sebaran Parasitoid & & & & & & \\
\hline A. lopezi & 4,2 & 8,4 & 4,6 & 7,2 & 3,4 & 3,2 & 6 & 4 & 4,4 \\
A. papaye & 1,2 & 1,6 & 1 & 1 & 2,6 & 0,6 & 0,8 & 1,2 & 0,4 \\
$\begin{array}{l}\text { B. } \\
\text { insularis }\end{array}$ & 0,6 & 0,4 & 0,2 & 0,6 & 1 & 0,4 & 0,6 & 0,6 & 0,4 \\
\hline
\end{tabular}

Kemampuan parasitoid dalam parasitoid untuk mencari inang di lapang penyebaran tentu saja dipengaruhi oleh faktor (Van Driesche et al., 2008).

abiotik dan biotik pada masing-masing daerah pertanaman ubi kayu di lapang. Faktor biotik seperti tanaman inang yang tersebar di lapang sangat mempengaruhi persebaran parasitoid sehingga parasitoid dapat memencar secara aktif, terbawa melalui angin, atau terbawa melalui mumi yang menempel pada stek bibit (Abduchalek, 2016). Di Afrika dilaporkan parasitoid $A$. lopezi mampu memencar dengan laju 50-100 km (Herren et al., 1991). Faktor tanaman inang yang mempengaruhi persebaran dari parasitoid yaitu ketersediaan tanaman ubi kayu yang sesuai bagi kehidupan kutu putih P. manihoti.

Senyawa kimia yang dikeluarkan oleh tanaman (kairomon) dan material yang bersumber dari kotoran inang (embun madu), sekresi (sutra, kelenjar ludah, penanda feromon) yang dihasilkan oleh kutu putih dapat mempengaruhi persebaran dari

\section{SIMPULAN}

Morfologi parasitoid hama P. manihoti memiliki karakteristik yang sama dengan ketiga jenis parasitoid yang ditemukan yaitu Anagyrus lopezi, Acerophagus papayae dan Blepyrus insularis. Kelimpahan parasitoid didominanasi oleh parasitoid A. lopezi, kemudian disusul oleh parasitoid A. papaya dan B. insularis. Pola sebaran parasitoid bervariasi pada masing-masing spesies, parasitoid A. lopezi menyebar secara mengelompok, Parasitoid A. papayae dan $B$. insularis menyebar secara acak-teratur pada pertanaman ubi kayu diseluruh Kabupaten di Bali.

\section{UCAPAN TERIMA KASIH}

Penulis mengucapkan terima kasih kepada Prof. Dr. Ir. I Wayan Supartha, MS selaku Ketua Laboratorium Integrated Pest Management (IPMLaB) Fakultas pertanian 
UNUD yang telah memberikan fasilitas dan bantuan pendanaan dari Hibah Penelitian Grup Riset Tahun 2019 dengan Nomor Kontrak 11187/UN.14.2.6.11/LT/2019.

\section{DAFTAR PUSTAKA}

Abduchalek, B. (2016). Kutu Putih Singkong Phenacoccus manihoti Matile-Ferrero (Hemiptera: Pseudococcidae): Persebaran Geografi di Pulau Jawa dan Rintisan Pengendalian Hayati. (Tesis). Bogor (ID): Institut Pertanian Bogor.

Andow, D.A. (1991). Vegetational diversity and arthropod population response. Ann Rev Entomol 36: 561-586.

Altieri, M.A., C.I, Nicholls. (2004). Biodiversity and Pest Management in Agroecosystems. Haworth Press, New York.

Amarasekare, K.G., Mannion, C.M., Osborne, L.S., Epsky, N.D. (2008). Life history of Paracoccus marginatus (Hemiptera:Pseudococcidae) on four host plant species under laboratory conditions. Environ. Entomol. 37(3):630-635.

Aquilino, K.M., B.J, Cardinale., A.R, Ives., (2005). Reciprocal Effects Of Host Plant and Natural Enemy Diversity on Herbivore Suppresion: an Emoirical Study of a Model Tritrophic System. Oikos 108: 275-282.

Baggen, L.R, G.M, Gurr. (1998). The influence of food on Capidosoma koehleri (Hymenoptera: Encyrtidae), and the use of flowering plants as habitat management tool to enhance biological controlof potato moth, Phthorimaea operculella (Lepidoptera: Gelechiidae). Bio Cont. 11:9-17.

Giardanengo, P., J.P, Nenon. (1990). Melanization and encapsulation of eggs and larvae of Epidinocarsis lopezi by its host Phenacoccus manihoti; effect of superparasitism and egg laying patterns. Entomol Exp Appl. 56(2):155163.

Hayat, M. (2006). Indian Encyrtidae (Hymenoptera: $\quad$ Chalcidoidea). Department of Zoology, Aligarh, India. Aligarh Muslim University Press.

Herren, H.R., R.P, Neuenschwander. (1991). Biological control of cassava pests in Africa. Ann Rev Entomol. 36:257-283.

James, B., J, Yaninek., P, Neuenschwander., A, Cudjoe., W, Modder., N, Echendu., M, Toko. (2000). Pest Control in Cassava Farms. Nigeria (NG): Wordsmithes Printers Lagos.

Krebs, C.J. (1989). Ecological Methodology. New York: Harper \& Row Inc. Publisher.

Lohr, B., A.M, Varela. (1990). Exploration for natural enemies of the cassava mealybug, Phenacoccus manihoti (Homoptera: Pseudococcidae), in South America for the biological control of this introduced pest in Africa. Bulletin of Entomological Research 80, 417425.

Muniappan, R., B.M, Shepard., G.W, Watson., G.R, Carner., A, Rauf., D, Sartiami., P. Hidayat., J.V.K. Afun., G. Goergen., A.K.M.Z. Rahman. (2011). New records of invasive insects (Hemiptera: Sternorrhyncha) in Southern Asia and West Africa. J Agr and Urban Entomol. 26(4):167-174.

Nicholls, C.I., M.A, Alfieri. (200)3. Designing spesies-rich, pest-suppresive agroecosystem through habitat management. (diunduh 2019 Mei 5). Tersedia pada: http://agroeco.org.thrasillmaterialldesig ningspesies.htm.

Noyes JS. (2000). Encyrtidae of Costa Rica (Hymenoptera: Chalcidoidea), The subfamily Tetracneminae, parasitoids of mealybugs (Homoptera: Pseudococcidae). Memoirs of the 
I KADEK WISMA YUDHA. et al. Karakteristik Morfologi dan Kelimpahan Populasi...

American Entomological Institute. 62, 195.

Noyes, J.S., M, Hayat. (1994). Oriental Mealybug Parasitoids of the Anagyrini (Hymenoptera:

Encyrtidae).

Cambridge (GB): University Press.

Nwanze, K.F., Leuschner, K., Ezumah, H.C. (1979). The cassava mealybug, Phenacoccus manihoti in the Republic of Zaire. PANS 25(2): 125-130.

Nwanze, K.F. (1982). Relationship between cassava root yields and crop infestationsby the mealybug, Phenacoccus manihoti. Trop Pest Manag. 28:27-32.

Parsa, S., Kondo, T., Winotai, A. (2012). The cassava mealybug (Phenacoccus manihoti) in Asia: First records, potential distribution, and an identification key. PloS ONE 7(10): e47675.

Paulsen, H.M., M, Schochow., B, Ulber., S, Kühneand., G, Rahmann. (2006). Mixed cropping systems for biological control of weeds and pests in organic oilseed crops. Aspects of Applied Biology. 215:220.

Supartha, I.W. (2003). Parasitoids fauna diversity of Liriomyza spp. on vegetable crop in Bali and Lombok of Indonesia. 4th Congress of Indonesian Entomological Society and Symposium 2003. Cipayung Bogor (Indonesia) 3-7 March 2003. (Indonesian).

Supartha, I.W., I.G.N, Bagus., P, Sudiarta. (2005). Population abundance of Liriomyza spp. (Diptera: Agromyzidae) and parasitoids on highland vegetables $\begin{array}{llll}\text { crop. Agritrop } 24 & \text { (2): } & \text { 51-5.9 }\end{array}$ (Indonesian)

Van-Driesche, R.G., M, Hoddle., T, Center. (2008). Control of Pests and Weeds by Natural Enemies: an Introduction to Biological Control. Victoria (AU): Blackwell Publishing. hlm 16-18. pp 473.
Wardani, N. (2015). Kutu putih ubi kayu Phenacoccus manihoti Matile-Ferrero (Hemiptera: Pseudococcidae), hama invasif baru di Indonesia [disertasi]. Bogor (ID): Institut Pertanian Bogor.

Wahyuni, S., IW. Supartha., R. Ubaidillah., IN. Wijaya. (2017). Parasitoid Community Structure of Leaf Miner Liriomyza spp. (Diptera: Agromyzidae) and The Rate of Parasitization on Vegetable Crops in Lesser Sunda Islands, Indonesia. J. Biodiversitas. 18(2): 593-600..

Winotai, A., Goergen, G., Tamo, M., Neuenschwander, P. (2010). Cassava mealybug has reached Asia. Biocontrol News Inf. 31:10-11

Wyckhuys, K.A.G., Rauf, A., Ketelaar, J. (2014). Parasitoid introduced into Indonesia: part of a region-wide campaign to tackle emerging cassava pests and diseases. Biocontrol News and Inf. 35(4):35-37. 